\section{A large delayed esophageal perforation due to chicken bone impaction treated by over-the-scope clipping}

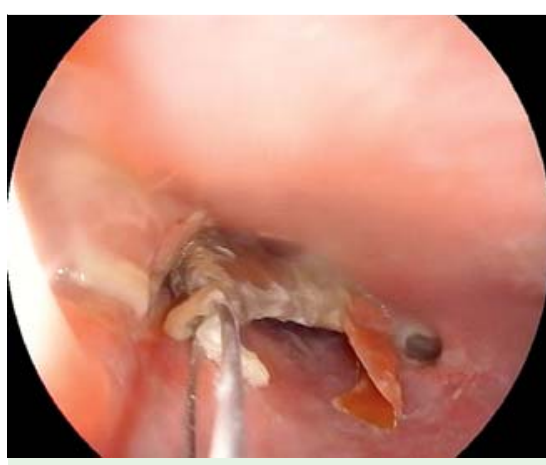

Fig. 1 Endoscopic view showing an impacted chicken bone in the cervical esophagus being removed with a snare.

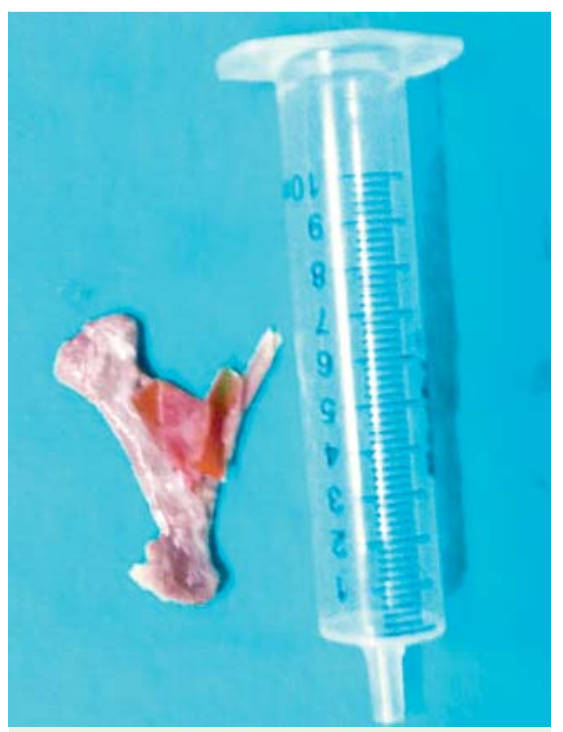

Fig. 2 Photograph of the chicken bone after its removal.
A 73-year-old man was admitted to the emergency clinic with a 7-day history of dysphagia after eating chicken. He had no significant medical history. On admission, he was tachypneic and tachycardic, but otherwise there were no significant findings on physical examination. His laboratory results showed a creatinine of $1.6 \mathrm{mg} / \mathrm{dL}$ and white blood count of $22400 / \mathrm{mm}^{3}$ but other measurements were within normal limits. Cervical and thoracic computed tomography (CT) scanning showed a foreign body in the esophagus and evidence of mediastinitis. Upper gastrointestinal endoscopy revealed a chicken bone in the cervical esophagus ( $\bullet$ Fig. 1 ). This was removed with a snare ( $\bullet$ Fig. 2 ) and, once this had been done, an esophageal perforation was revealed ( $\bullet$ Fig.3a). We applied an overthe-scope clip (OTSC; Ovesco) for the esophageal perforation 2 days after admission using an endoscope with a diameter of $12 \mathrm{~mm}$, cap depth of $6 \mathrm{~mm}$, and a clip with pointed teeth (OTSC t) ( $\bullet$ Fig. $3 \mathbf{b})$.

We subsequently decided, 5 days after his admission, that the patient should undergo a thoracotomy because of mediastinitis. A right thoracotomy was performed and descending necrotizing mediastinitis was detected. The mediastinal cavity was cleaned with saline and betadine solution and the operation was completed by inserting a drain. After 25 days of medical therapy with antibiotics, the patient was discharged.

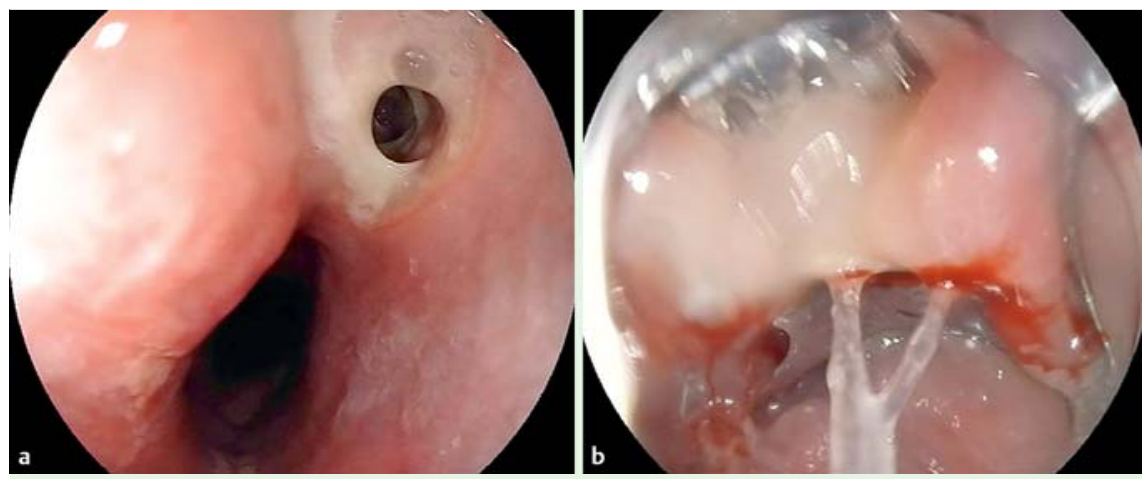

Fig. 3 Endoscopic views after the impacted bone had been removed showing: a a large esophageal perforation; $\mathbf{b}$ the application of an over-the-scope clip (OTSC).
The majority of ingested foreign bodies that enter the esophagus pass through the gastrointestinal tract, but $10 \%-20 \%$ of them require endoscopic intervention [1]. According to a meta-analysis, OTSC can be used for treatment of early (within 24 hours) esophageal perforations causing limited injury and contamination [2]. However, because of the increased risk of morbidity and mortality due to major esophageal surgery, we used an OTSC followed by limited surgical thoracic washing and cleaning.

Endoscopy_UCTN_Code_TTT_1AO_2AI

\section{Competing interests: None}

\section{Ahmet Yozgat ${ }^{1}$, Faruk Cetin ${ }^{1}$, Yucel Akkas $^{2}$, Enver Avci ${ }^{1}$, Ersan Ozaslan ${ }^{1}$}

${ }^{1}$ Department of Gastroenterology, Ankara Numune Education and Research Hospital, Ankara, Turkey

${ }^{2}$ Department of Thoracic Surgery, Ankara Numune Education and Research Hospital, Ankara, Turkey

\section{References}

1 Birk M, Bauerfeind P, Deprez PH et al. Removal of foreign bodies in the upper gastrointestinal tract in adults: European Society of Gastrointestinal Endoscopy (ESGE) Clinical Guideline. Endoscopy 2016; 48: 489-496

2 Lazar G, Paszt A, Man E. Role of endoscopic clipping in the treatment of oesophageal perforations. World J Gastrointest Endosc 2016; 8: 13-22

Bibliography

DOI http://dx.doi.org/

10.1055/s-0042-111322

Endoscopy 2016; 48: E253

(c) Georg Thieme Verlag KG

Stuttgart · New York

ISSN 0013-726X

Corresponding author

Ahmet Yozgat, MD

Baskent Bulvari 224/B Atlantis City Sitesi

Yosun Blok No:78 Batıkent

Ankara

Turkey

a_yozgat@yahoo.com 